\title{
A CONTENT ANALYSIS OF YOUTH SEXUALIZED LANGUAGE AND IMAGERY IN ADULT FILM PACKAGING, 1995-2007
}

\author{
Robin E. Jensen
}

This study defines youth sexualized language (YSL)-language that sexually objectifies young people/youth (i.e. individuals who look like they could be minors) —and youth sexualized imagery (YSI)_photographs, drawings, or other visual depictions that sexually objectify young people/youth-and quantifies the frequency of both in mainstream adult film packaging. A content analysis of 2,600 randomly selected mainstream adult film covers released from 1995 to 2007 revealed that over 20 per cent of covers contained YSL, YSI, or both, including references to and depictions of teens, braces, pigtails, stuffed animals, and school uniforms. The analysis also revealed that adult film covers containing YSL and/or YSI overwhelmingly sexualized characters coded as female rather than as male or transgendered.

KEYWORDS content analysis; child pornography; gender; media; pornography; youth sexualized imagery; youth sexualized language

Over the last three decades, the hypersexualization of children, especially girls, has garnered the attention of parents, media researchers, and policy makers. Concerns ignited following media scandals such as those surrounding the 1981 Calvin Klein advertising campaign featuring 15-year-old Brooke Shields whispering "Know what comes between me and my Calvins? Nothing!" and the 1996 murder of the child beauty queen JonBenét Ramey. Today, toy stores cannot keep Bratz dolls, which are decorated in heavy make-up and barely-there mini skirts, on the shelves, and popular clothing chains stock thong underwear for pre-adolescent girls with phrases such as "Little Hottie" and "Wink, Wink." Levin and Kilbourne (2008) and Durham (2008) have argued that this widespread sexualization of girls (what Durham calls "the Lolita effect") exploits children and puts their self-image and wellness at risk. More specifically, the American Psychological Association (APA) Task Force on the Sexuality of Girls (2007) reported that sexualizing girls can result in their impaired cognitive functioning, poor motor performance, and a range of mental health disturbances such as depression, eating disorders, and low self-esteem.

In addition, Walkerdine (1997), Merskin (2004), and Jensen and Dines (1998) maintained that sexualizing children in the media fosters a pedophilic gaze, a point Jensen and Dines evidenced by describing the youth sexualizing content in adult films and arguing that their "clear intent was to sexualize the age difference, to point out the erotic charge of having a teenager satisfy an adult's sexual desire" (p. 89). Indeed, even a brief examination of mainstream adult film covers reveals material that sexualizes youth. For example, 2008 saw the release of Barely Legal \#82, the 82 nd installment in Hustler's Barely Legal series. Like its predecessors, Barely Legal \#82 depicted a woman who had apparently just turned 
18 who was having sex for the first time. The cover of the film boasted the words "Barely Legal" and featured a young woman in pigtails, wearing a truncated school girl uniform, and surrounded by school books, pencils, and notebook paper. The woman was described as a "little darling" who had turned into a "sexpot," thus blurring the distinction between child and adult.

In a recent experimental study, Paul and Linz (2008) set out to explore the effects of exposure to this type of "barely legal" pornography-which they defined as "sexually explicit depictions of females who appear to be minors"-and found that it produced a "child-sex cognitive schema" (p. 3). Some participants were exposed to barely legal pornography and others were exposed to "adult" pornography. Those who viewed barely legal pornography were quicker than their counterparts to recognize sexual words when they viewed images of young girls that were not explicitly sexual in nature. Although Paul and Linz's study did not provide evidence that such a schema made individuals more likely to seek out sexual interactions with minors, the research demonstrated that exposure to youth sexualizing materials (e.g. materials that sexually display or reference those who appear to be minors) created cognitive links between sex and minors that were not necessarily evident without such exposure.

Several questions are raised by Paul and Linz's (2008) study, perhaps the most immediate of which is: how common is barely legal pornography? Barely legal pornography, or what Lederer (1995) and Jensen (2007) have both labeled pseudochild pornography, is an example of a larger category of communication that I call youth sexualized language (YSL) - language that sexually objectifies young people/youth (i.e. individuals who look like they could be minors) — and youth sexualized imagery (YSI)—photographs, drawings, or other visual depictions that sexually objectify young people/youth. If YSL and YSI are rare, then the significance of Paul and Linz's findings are somewhat muted. However, if YSL and YSI are as common as Hustler's (2008) series of eighty-two plus films suggests, then researchers have identified a social issue in need of attention. After all, the more prevalent this content is, the more opportunities there are to prime the "child-sex cognitive schema" and contribute to the mediated hypersexualization of children. And researchers representing a range of theoretical viewpoints have argued that mediated messages can play a role in shaping viewers' attitudes and behaviors. Bandura's $(1977,1986)$ social learning theory posits that individuals learn how to act by observing others interacting with the world around them. From this perspective, adult film covers that feature youth sexualizing language and imagery may function as models for viewers who then learn to sexualize minors and/or to seek out sex with minors. Similarly, the theory of normative social behavior (Lapinski \& Rimal, 2005; Rimal \& Real, 2003) holds that representations and perceptions of attitudes and behaviors as normative play a role in individuals adopting those attitudes and behaviors themselves. For instance, if individuals repeatedly see portrayals of youth sexualizing language and imagery, they may come to believe that such language and imagery represents what most people see as normal and therefore that they should view minors as sexual and/or as potential sex partners. In addition, cultivation theory (Gerbner, Gross, Morgan, \& Signorielli, 1986; Signorielli \& Morgan, 2001) holds that individuals cultivate world views as a result of exposure to mediated messages. Youth sexualizing media messages, in this light, may cultivate in audiences the view that, for instance, many adults see minors as sexually attractive and available.

The present study seeks to begin the process of quantifying the frequency of barely legal pornography via a content analysis of youth sexualized language and imagery on 
adult film covers from 1995 to 2007. The purpose of the study is to define youth sexualized language and imagery, quantify the frequency and types of youth sexualized language and imagery on adult film covers, and explore what those framings might mean for society in terms of media, health, and sexuality.

\section{Youth Sexualized Language and Imagery}

Youth sexualized language and imagery can be defined most clearly against the backdrop of the legal context in which they have emerged. According to the US Federal Crimes \& Criminal Procedure Rule (2006), child pornography is any visual representation (e.g. photograph, drawing, graphic) of a person who is (or appears to be) under 18 years of age engaged in sexual activity or whose sex organs are exposed, and/or any textual or visual communication suggesting sex with a minor person. In 2008, the Supreme Court upheld the Prosecutorial Remedies and Other Tools to End the Exploitation of Children Today (Protect) Act (2003), which included the provision that "it is not a required element of any offense under this section that the minor depicted actually exist" (p. 681). The PROTECT Act replaced the 1996 Child Pornography Prevention Act in which an offense required the depiction of real minors. Thus, whether depictions are digitally-created/altered or not, producing, distributing, and/or possessing such material is illegal and punishable by imprisonment, fines, and/or, in some cases, institutionalization.

In this context, the designation of pornography as depicting barely legal characters communicates that onscreen personalities are beyond the 18-year point of legality but still very young. Paul and Linz (2008) delineated "barely legal" pornography as opposed to "adult" pornography, noting that the former referenced featured characters' youth and lack of sexual experience. Barely legal pornography is a specific type of youth sexualized language and imagery. Youth sexualized language (YSL) is any language that sexually objectifies those who look like they might be minors (i.e. those who are under 18 years of age). YSL can take many forms ranging from explicit discussions about having sex with young people (e.g. sex with young girls, teens losing their virginity) to more figurative communication about engaging young people in sexual activities (e.g. pop her cherry, teach teens to please). As Paul and Linz explained, even language and imagery that explicitly labels itself legal (i.e. not including minors) can create cognitive pathways linking minors and sex. For instance, a mention of "cheerleaders" may literally reference people who are over 18 years of age, but the traditional symbolism of cheerleaders as "promiscuous," underage teenagers (Fine \& Johnson, 1980, p. 121) may remain intact in consumers' minds. Similarly, using the word "legal" references what a sexualized subject looks to be, which is underage and therefore illegal. For if a character did not seem as if she might be too young to be featured in an adult film, there would be no need to label the film legal. Thus, although youth sexualized language and imagery on adult film covers may not legally constitute child pornography, it may still serve to sexualize minors.

Youth sexualized imagery (YSI) refers to photographs, drawings, or other visual depictions that sexually objectify people who look like they might be underage. YSI can take many forms that range from characters sexualizing activities that are traditionally associated with youth (e.g. licking a lollipop, having a slumber party; Kleinhans, 2004) to drawings of symbols traditionally associated with youth on a sex-related product (e.g. colorful hearts, butterflies, and flowers or notebooks, backpacks, and lockers on an adult film cover; Higonnet, 1998; Jensen, 2007). What separates YSI from youth-related 
imagery or sexual imagery is that it pairs the two, drawing from cultural symbols of or products related to sex (e.g. condoms, sex toys) and from cultural symbols of youth or products related to youth (e.g. hairstyles typically worn by children such as pigtails, children's clothing such as saddle shoes; Higonnet, 1998). YSI does not feature underage individuals but utilizes a variety of visual images that reference those who look to be minors and, because they are featured on an adult film cover designed to sell sex, suggest sex with minors. For example, a featured actress may not truly be underage but by wearing pigtails in her hair and a school girl skirt while also posing in a sexually suggestive way, adult film marketers signal that she is underage and sexually available to adult partners (i.e. those individuals 18 years of age or older who are eligible to purchase adult films).

Although YSL and YSI may mirror child pornography, child pornography is not a type of YSL or YSI because child pornography features minor characters on sexual display and/or engaged in sexual behaviors. By contrast, YSL and YSI are characterized by content that features people who only look like they are under the age that they can legally consent to sex with an adult. For this reason, YSL/YSI and child pornography are different categories of sexual communication.

\section{Prior Content Analysis and Qualitative Research}

A number of researchers have examined pornographic material and its content. Content analysts have identified several common themes in mainstream pornography including violence and sexual aggression (Barron \& Kimmel, 2000; Dietz \& Sears, 1987/1988; Glascock \& LaRose, 1993; Gossett \& Byrne, 2002; Malamuth \& Spinner, 1980; Palys, 1986; Scott \& Cuvelier, 1987, 1993; Yang \& Linz, 1990); stereotypical/distorted racial depictions (Cowan \& Campbell, 1994; Mayall \& Russell, 1990; Winick, 1985); and the sexual objectification of women (Bogaert \& Turkovich, 1993; Cowan, Lee, Levy, \& Snyder, 1988; McKee, 2005; Smith, 1976).

No content analysis has addressed youth sexualized content in adult film packaging, but several qualitative studies have addressed this topic. Palmer (1979) found that comics in pornographic magazines repeatedly included themes such as defloration/loss of virginity, incest, permissive and seductive parenting, and sex between adults and adolescents. Heider and Harp (2002) reported that pornographic websites often described characters as youthful, employing adjectives such as "teen" and "young" and depicted them toting school books and wearing school uniforms (p. 295). Similarly, Jensen and Dines (1998) noted that mainstream adult videos often included portrayals of young girls "learning" how to have sex under the tutelage of older men. But despite the convincing arguments that have been made about the youth sexualized content in mainstream pornographic material such as cartoons, websites, and videos, there has been no attempt to quantify that content (or the packaging of that content); this is a project taken up in the present research.

\section{Research Questions}

The present study seeks to quantify the amount of youth sexualized content on adult film covers, which serve as the packaging that potential consumers (i.e. those who are 18 years of age or older) view when deciding whether or not to purchase an adult film. More importantly, adult film covers offer insight into how the adult film industry packages 
and therefore markets pornography. This is significant because youth sexualized content does not literally sexualize minors (the actors and actresses are of legal age) but rather markets legal adults as minors. If the adult film industry is repeatedly marketing its products in specific ways, regardless of products' actual content, the industry is either targeting a market that already exists or actively working to create consumers with certain sensibilities and desires (APA, 2007). Whatever the case may be, an assessment of whether YSL and/or YSI is featured on adult film covers is an important first step in delineating the frequency of YSL and YSI in sex-related media and the media in general.

The present study is interested in the existence of youth sexualized language in the packaging of pornographic materials. Thus, the study seeks to quantify YSL on adult film covers.

RQ1: What is the frequency of youth sexualized language on mainstream adult film covers?

Not only is it important to explore whether YSL exists on adult film covers, it is also important to assess if the amount of YSL on adult film covers has changed over time. A trend toward more or less YSL on adult film covers could demonstrate a change in the cultural landscape.

RQ2: Has the frequency of youth sexualized language on mainstream adult film covers changed over time?

In addition to language, the present study is interested in the existence of visual depictions of youth sexualization in the packaging of pornographic materials. Thus, the study seeks to quantify YSI on adult film covers.

RQ3: What is the frequency of youth sexualized imagery on mainstream adult film covers?

Not only is there a need to know if YSI exists on mainstream adult film covers, but it is also useful to examine if the amount of YSI on covers has changed over time. As in the case of YSL, a trend toward more or less YSL on adult film covers could demonstrate a change in the cultural landscape.

RQ4: Has the frequency of youth sexualized imagery on mainstream adult film covers changed over time?

Paul and Linz (2008) limited their study by defining barely legal pornography as pornography that features female subjects who appear to be minors, but YSL and YSI may sexualize constructions of gender other than female. Researchers have argued that the gender construction of sexualized subjects in pornographic materials may play an important role in enforcing (and re-enforcing) sex roles, sexual dominance, and sexual aggression (Heider \& Harp, 2002; Kuhn, 1985). Thus, there is a need to know which gender constructions are featured in YSL and YSI on mainstream adult film covers and in what frequency, and an exploration of the gender of the sexualized subject is included in the analysis.

RQ5: What is the gender of the sexualized subject on mainstream adult film covers that include youth sexualized language and/or youth sexualized imagery? 


\section{Method}

\section{Sample}

A random sample of 200 film covers per year from 1995 to 2007 was collected from the website adultdvdempire.com $(N=2,600)$. This website was selected because it has been named the "best retail adult film website" for the last 5 years by the US adult video industry at the Adult Video News (AVN) awards (Adult Video News, 2008). This award is given to the site that is the most comprehensive and has the highest number of adult film sales, and thus the winner offers the most representative sample of mainstream adult film covers currently available to the public. 1995 was selected as the starting point for coding as that year marked the first hearings leading up to the passage of the Child Pornography Prevention Act (S. 1237, 1996), which dramatically restricted child pornography and made producing and consuming sexual messages about minors more perilous than it had been in years past.

\section{Content Categories}

Front film covers (not the back or sides) served as the unit of analysis for this study. Each film cover in the sample was enlarged so that it was possible to read the text and see the images clearly. The covers were coded individually for whether YSL was present or not, and, if YSL was present, what specific words or phrases were evident (i.e. coders wrote out the words or phrases that constituted YSL on each cover). The coders grouped individual instances of YSL into categories of unique textual content. These categories were drawn from prior research identifying symbols that function as "social representations" (Lloyd \& Duveen, 1990, p. 27) for childhood and/or youth (Higonnet, 1998; Jensen, 2007; Jensen \& Dines, 1998; Kincaid, 1998; Kleinhans, 2004; Paul \& Linz, 2008), as well as constant comparative methodology (Glaser, 1992; Strauss \& Corbin, 1990). The categories include (1) adjectives (e.g. cute, sweet, fresh) [in the context of pornographic packaging where adjectives such as "hot" or "sexy" are logically more conducive to products' traditional goals than are "cute" or "sweet," the research team followed the reasoning of Higonnet who argued that such adjectives signaled "youth" in ways they might not in other contexts (p. 77)]; (2) age (e.g. 18-24 years old) [although the 18-24 age range is not technically underage, it is as young as the adult film industry can claim actresses and actors are without being found guilty of producing child pornography; in this sense, the age range is marketing (and valorizing) youth to the extent the adult film industry can do so without breaking the law (Paul \& Linz, 2008, p. 3)]; (3) culture (e.g. hide and go seek, Mother Goose; Higonnet, 1998, p. 56); (4) endearment (e.g. sweetie, cutie; Jensen, 2007, p. 90); (5) food (e.g. cherries, candy; Kleinhans, 2004, p. 22); (6) legality (e.g. barely legal; Paul \& Linz, 2008, p. 3); (7) school (e.g. straight A's, homeroom, college; Jensen, 2007, p. 126) [although language that discusses "college" often refers to young people who are not minors, textual appeals of this nature can be ambiguously referring to activities in which minors often engagecheerleading, taking tests, writing on the chalkboard-and in which people who are young but legal also engage; the research team concluded that the emphasis on school-related activities, even if those activities are set in a college or other post-high school venue, can function as symbols of minor individuals]; (8) teen (Jensen \& Dines, 1998, p. 89); (9) virginity (Kincaid, 1998, p. 126); (10) words children use (e.g. diary, naughty; Kincaid, 1998, p. 104); and (11) youth descriptors (e.g. starlet, innocent, debutante; Jensen, 2007, p. 124). 
By contrast, some examples of language that coders did not count as YSL, but that potentially could be interpreted as YSL, are (1) references to size (e.g. little, tight, small) [the research team decided that the size of a person did not necessarily correspond with a person's age]; (2) terms frequently used to refer to both young and more mature people (e.g. chicks, girls, boys, hotties); (3) references to newness not directly associated with sex (e.g. amateur, prospect) [the research team concluded that being inexperienced with an activity does not necessarily correspond with a person's age]; (4) terms of endearment not primarily associated with youth (e.g. darling, beautiful); and (5) references to media targeted at children and adults (i.e. Crouching Tiger, Hidden Dragon).

In addition, the film covers were coded individually for whether YSI was present or not, and, if YSI was present, what unique instances of YSI were evident (i.e. coders used their own words to describe the imagery that constituted YSI on each cover). Images containing YSI were grouped into the following categories: (1) appearance of the sexualized subject (e.g. schoolgirl uniforms-plaid, pleated skirts with white, collared shirts and blue blazers, or some combination thereof, pigtails, braces; Jensen, 2007, p. 73); (2) background drawings (e.g. drawings of cartoon characters that resemble those seen in children's media, drawings of items that denote sexual innocence such as cherries, child-like drawings that do not adorn font; Kleinhans, 2004, p. 22); (3) font (e.g. adorned with flowers and hearts as seen on products marketed to young children, marker/crayon writing, looks to have been written in a wide-ruled notebook most often used in elementary and secondary schools; Higonnet, 1998, p. 70; Jensen, 2007, p. 126); (4) props (e.g. lollipops, stuffed animals, school books; Higonnet, 1998, p. 193; Kleinhans, 2004, p. 22); (5) relationship between sexualized subject and sexualizing subject (e.g. student-teacher, child-parent, sports' team member-coach; Kleinhans, 2004, p. 26); and (6) setting (e.g. high school hallway, child's birthday party, dorm room; Jensen, 2007, p. 89).

By contrast, some examples of imagery that coders did not count as YSI, but that potentially could be interpreted as YSI, include (1) women's underwear or lingerie adorned with hearts, ribbons, or flowers (the research team decided that many women's undergarments are adorned with and styled in ways that are traditionally associated with young girls and therefore coding for those undergarments on covers may exaggerate the degree of youth sexualization therein); (2) hairstyles that are commonly worn by adults and children (e.g. ponytails); (3) sex toys (e.g. dildos); (4) settings that do not serve children exclusively (e.g. carnivals, beaches, swimming pools); and (5) drawings of stars that denote film ratings.

After the initial phase of coding, the coders engaged in secondary coding. First, each cover that contained YSL, YSI, or both was coded for gender of the sexualized character (or implied character) as male (i.e. subjects explicitly labeled as male or "he" and/or featuring male secondary sex characteristics), female (i.e. subjects explicitly labeled as female or "she" and/or featuring female secondary sex characteristics), transgender (i.e. subjects explicitly labeled as transgender or "she/he" and/or featuring male and female secondary sex characteristics), or unclear (i.e. subjects without any gendered labeling or visible secondary sex characteristics).

Second, the unique instances of YSI were further divided into subcategories using constant comparative methodology (Glaser, 1992; Strauss \& Corbin, 1990), as well as attention to existing theoretical investigations establishing links between symbols and the notion of childhood (Adams \& Bettis, 2003; Cook \& Kaiser, 2004; Driscoll, 2002; Higonnet, 1998; Jensen, 2007; Kleinhans, 2004), and coded accordingly to better distinguish 
their content. Subcategories for appearance of the sexualized subject included braces, cheerleading outfits (e.g. cheerleading uniforms with school names or logos printed on the fabric; Adams \& Bettis, 2003, p. 86), children's clothing (e.g. lace fold-over socks, Mary Janestyle shoes, baby doll dresses; Cook \& Kaiser, 2004, p. 200; Higonnet, 1998, p. 155), pigtails (Kleinhans, 2004, p. 22), schoolgirl uniforms (e.g. plaid skirts and vests, blue blazers, knee socks; Jensen, 2007, p. 73), and other. Subcategories for props included references to food (e.g. sweets associated with children such as candy, fruit associated with virginity such as cherries; Kleinhans, 2004, p. 22), pom poms (Jensen, 2007, p. 90), school-related items (e.g. notebooks, backpacks; Jensen, 2007, p. 126), toys (e.g. teddy bears, bouncy balls; Higonnet, 1998, p. 81), and other. Subcategories for setting included school (e.g. classrooms with chalkboards and children's desks; Jensen, 2007, p. 126), child's bedroom (e.g. rooms prominently featuring a bed decorated with stuffed animals and other children's toys; Driscoll, 2002, p. 257), and other. Subcategories for relationship between sexualized subject and sexualizing subject included teacher (i.e. one character acts as an instructor to another character who acts as a student), parent (i.e. one character acts as a "daddy" or "mommy" in relationship to another character who acts as that character's child), bus driver (i.e. one character drives a bus or school transportation vehicle and knows the other character because he/she is a student who needs to be transported home), and other (Kleinhans, 2004, p. 26). Subcategories for font included adornment (e.g. glitter, hearts in place of dotted i's; Higonnet, 1998, p. 70), child-like/sloppy writing, notebook writing (i.e. writing that is literally placed within the lines of a notebook or takes the shape of block letters written with a pencil; Higonnet, 1998, p. 70; Jensen, 2007, p. 126), and other. And subcategories for background drawings included cartoons that resemble those featured in children's media, drawings of hearts, butterflies, and the like that resemble those featured on children's products and in children's media (Jensen, 2007, p. 83), drawings of schoolrelated items (e.g. crayons, school desks; Higonnet, 1998, p. 70; Jensen, 2007, p. 126), drawings of toys (e.g. spinning tops, stuffed animals; Higonnet, 1998, p. 81), and other.

The coders followed several general rules to maintain consistency and reliability. First, coders were instructed to code a word or image only once for each unit of analysis (i.e. front film cover). That is, if the word "teen" appeared twice on one cover, it would only be recorded once. However, if the words "teen" and "barely legal" appeared on the same film cover, both of those terms would be coded as unique instances of YSL (although the cover itself would only be "counted" once toward the overall number of covers that contain YSL). Second, coders were instructed to be consistent between coding for language and coding for imagery. For instance, if a coder decided to code for the image of a popping cherry (YSI), the coder would also code for the word "popping cherry" (YSL) if it was also present on the cover. Third, coders were instructed not to code for background images that were not directly relevant to the scene and were not unusual to that scene. For example, a vase of flowers on a table in the background of a kitchen scene would not be coded as it is common for film directors (and home decorators) to utilize such imagery without sexual intent or meaning attached to it.

\section{Training and Coding}

One female and one male (the author and a faculty colleague, respectively) served as coders for this study. The research team created the coding scheme by carefully isolating and analyzing a random sample of 400 adult film covers. The coders completed four 
in-depth training sessions before they began coding for this study. Each training session consisted of both coders coding the same 100 covers and then carefully going over their choices with each other to discuss their interpretations of the coding scheme. After the coders completed the training sessions, a sample of 800 films was jointly coded. Cohen's Kappa was calculated for each content variable. Kappa scores revealed solid reliability between coders, with high reliability scores for youth sexualized language (.95), youth sexualized imagery (.86), and gender of the sexualized object (.97). After reliability was established, the sample was divided in half (random samples of 100 film covers from each year were assigned to each coder) and coded.

\section{Results}

RQ1: YSL Frequency

The first research question concerned the frequency of YSL on mainstream adult film covers. Of the 2,600 film covers in the sample, 539 (20.7 per cent) included one or more forms of YSL. In other words, roughly one in five adult film covers contained some form of YSL.

Coders also divided individual instances of YSL into categories of unique instances of YSL. The categories of unique instances of YSL are listed in Table 1 in order of frequency (i.e. most frequent to least frequent). Each film cover could potentially contain more than one example of YSL (although repeated words were not counted more than once for each cover). There were 717 unique instances of YSL spread across 539 adult film covers. Youth descriptors were the most common category, constituting over a fifth of all YSL instances. Youthful adjectives, school-related references, and the word "teen" were other major categories. References to virginity, food, and legality were among the least common.

\section{RQ2: YSL Frequencies over Time}

The second research question asked whether YSL on mainstream adult film covers had increased over time. A regression analysis - with time as the independent variable (i.e. year the movie was released)—revealed a statistically significant linear trend,

\section{TABLE 1}

Unique YSL instances on adult film covers, 1995-2007

\begin{tabular}{lcc}
\hline & Frequencies & \% of unique YSL instances \\
Youth descriptors & 170 & 23.7 \\
Adjectives & 96 & 13.4 \\
School & 96 & 13.4 \\
Teen & 92 & 12.8 \\
Words children use & 73 & 10.2 \\
Age & 44 & 6.1 \\
Culture & 32 & 4.5 \\
Endearment & 29 & 4.0 \\
Virginity & 26 & 3.6 \\
Food & 23 & 3.2 \\
Legal & 22 & 3.1 \\
Other & 14 & 2.0 \\
$N$ & 717 & 100.0 \\
\hline
\end{tabular}

Note: There were 717 unique YSL instances across 539 adult film covers. 
$F(1,2598)=5.79, p=.01, R=.04, R^{2}=.002, B=.005(S E=.002)$. An examination of the regression line confirmed that YSL on adult film covers does appear to have slowly increased from 1995 to 2007. However, even though the trend line is statistically significant, it accounts for very little variance ( 0.2 per cent) in YSL. Thus, an accurate assessment of the data is that YSL did not meaningfully change over time.

\section{RQ3: YSI Frequency}

The third research question concerned the frequency of YSI on mainstream adult film covers. Of the 2,600 film covers in the sample, 567 (21.8 per cent) included one or more instances of YSI. That is, approximately one in five film covers contained some form of YSI.

Coders grouped examples of YSI into categories of unique instances of YSI (e.g. appearance) and then divided those categories into smaller units to reveal their specific features (e.g. braces, cheerleading outfits, children's clothing, pigtails, schoolgirl uniforms). The categories of unique instances of YSI, as well as the corresponding subcategories, are listed in Table 2 in order of frequency (i.e. most frequent to least frequent). Each film cover could potentially contain more than one example of YSI (although repeated imagery was not counted more than once for each cover). There were 751 unique instances of YSI spread across 567 adult film covers.

The largest category of YSI was font, with the vast majority of font-related YSI constituted by font adorned with cartoons, drawings, and/or glitter. The second largest category of YSI was characters' appearance, with over half of appearance-related YSI (51.2 per cent) constituted by characters wearing pigtails. Nearly a third of appearance-related YSI (32.7 per cent) was constituted by schoolgirl uniforms. A substantial amount of YSI consisted of background drawings of toys, hearts, flowers, butterflies, cartoons, and schoolrelated images.

There were very few YSI depictions that constituted setting or relationships. Some of the settings that were evident included schools and children's bedrooms. Some of the few relationships that were depicted included student-teacher, child-parent, and bus riderbus driver.

\section{RQ4: YSI Frequencies over Time}

The fourth research question asked whether YSI on mainstream adult film covers was increasing over time. A regression analysis - with time as the independent variable (i.e. year the movie was released)-revealed no significant linear trend, $F(1,2598)=3.52, p=.06$, $R=.03, R^{2}=.001, B=.004(S E=.002)$. An examination of the regression line confirmed that YSI did not significantly increase from 1995 to 2007.

\section{RQ5: Gender of Sexualized Subject}

The fifth research question concerned the gender of the sexualized subject on mainstream adult film covers that depicted YSL and/or YSI. Frequency calculations revealed that adult film covers that contained YSL and/or YSI $(N=850)$ overwhelmingly sexualized female subjects ( 94 per cent). A much smaller number of adult film covers sexualized transgender subjects ( 3 per cent) and an extremely small number of film 
TABLE 2

Unique YSI instances in adult video covers, 1995-2007

\begin{tabular}{|c|c|c|c|}
\hline & & Frequencies & $\%$ of unique YSI instances \\
\hline \multicolumn{4}{|c|}{ Font } \\
\hline & Adornment & 163 & 21.7 \\
\hline & Notebook writing & 71 & 9.4 \\
\hline & Child-like writing & 9 & 1.2 \\
\hline & Other & 1 & 0.1 \\
\hline \multicolumn{4}{|c|}{ Appearance } \\
\hline & Pigtails & 122 & 16.2 \\
\hline & Schoolgirl outfits & 78 & 10.4 \\
\hline & Cheerleader outfits & 15 & 2.0 \\
\hline & Children's clothing & 13 & 1.7 \\
\hline & Braces & 5 & 0.7 \\
\hline & Other & 5 & 0.7 \\
\hline \multicolumn{4}{|c|}{ Background drawings } \\
\hline & Hearts and flowers & 73 & 9.7 \\
\hline & Cartoons & 66 & 8.8 \\
\hline & Toys & 28 & 3.7 \\
\hline & School-related & 14 & 1.9 \\
\hline \multicolumn{4}{|c|}{ Props } \\
\hline & Food & 17 & 2.3 \\
\hline & Toys & 10 & 1.3 \\
\hline & School-related & 8 & 1.1 \\
\hline & Pom poms & 6 & 0.8 \\
\hline & Other & 9 & 1.2 \\
\hline \multicolumn{4}{|c|}{ Setting } \\
\hline & School & 16 & 2.1 \\
\hline & Child's bedroom & 7 & 0.9 \\
\hline & Other & 5 & 0.7 \\
\hline \multicolumn{4}{|c|}{ Relationship } \\
\hline & Teacher & 5 & 0.7 \\
\hline & Parent & 2 & 0.3 \\
\hline & Bus driver & 2 & 0.3 \\
\hline & Other & 1 & 0.1 \\
\hline$N$ & & 751 & 100.0 \\
\hline
\end{tabular}

Note: There were 751 unique YSI instances across 539 adult film covers.

covers sexualized subjects with unclear genders (1.2 per cent). Only one film cover sexualized a male subject.

\section{Discussion}

The results of the present study indicate that over 20 per cent of mainstream adult film covers contain YSL, YSI, or both, content that according to Paul and Linz (2008) may create a "child-sex cognitive schema" (p. 3). One of the most prominent findings resulting from this study was the frequency at which characters featured on adult film covers sported pigtails, a hairstyle traditionally worn by very young, female children (Shelton, 1997). A corresponding and also prominent finding was the rate at which the word "teen" was used to describe characters. Today, those perusing mainstream adult film covers are almost certain to witness female characters who are marked as very young by title and/or appearance engaging in sexual behaviors, sometimes with older, male partners. 
The finding that adult film covers with YSL/YSI sexualized females in the vast majority of cases rather than males or transsexuals corresponds with similar findings about the sexualization of female children in mainstream advertising (O'Donohue, Gold, \& McKay, 1997). The sexualization of girls in popular culture is particularly problematic because research demonstrates that situational sexual abuse of children (i.e. abuse that arises from opportunity or circumstance rather than an exclusive sexual preference for children) is more often committed against girls than against boys, with girls often serving as sexual replacements for adult female partners. Although boys are also frequent victims of sexual abuse, they are more likely than girls to be targeted by offenders who are exclusively attracted to children (Johnston \& Johnston, 1997). With females making up the overwhelming majority of subjects sexualized by YSL and YSI on mainstream adult film covers, such media may be playing a role in perpetuating situational sexual abuse against girls.

On the whole, the present study suggests that mainstream adult film companies are marking 20 to 22 per cent of their films in ways that glorify young female sex partners. Of course, adult film companies are not alone in this venture. The idea that younger sexual partners are desirable, that many adults are attracted to minors and behave in ways that communicate that attraction, appears to be present not only in pornographic materials but also in fashion magazines, television shows, blockbuster films, and beauty pageants (Giroux, 1998, 2000). This general trend toward the hypersexualization of girls in mainstream media (Cook \& Kaiser, 2004; Durham, 2008; Levin \& Kilbourne, 2008) demonstrates that even messages that technically do not constitute child pornography may be increasingly likely to foster the sexualizing of youth and the dangers to children and society that accompany such sexualization. Whereas attraction to children may once have been conceived of as an isolated fetish, it may now be a trope or discourse that is illustrated, marketed, and perpetuated in the mainstream media. And as Foucault (1979) maintained, one central focus of any discourse is to identify and then regulate what is considered normal by society. Those who encounter a discourse are immediately implicated in its logic and must either accept what the discourse values as normal or struggle to resist the dominant forces upholding the discourse. But such resistance may not be possible when the terms one must use to resist are ingrained in the discourse in question. In discourses that include portrayals of YSL/YSI, then, the perpetuation of messages that portray minors as sexual may be all but impossible to resist as long as those messages continue to circulate throughout mainstream society. MacKinnon (1993) argued that pornography in particular is ideologically potent (although not necessarily causal) in its social impact because eventually "consumers want to live out the pornography further in three dimensions" after repeatedly witnessing displays of certain types of desire unfold in pages and on screens (p. 19). She held that symbolic representations of sex with children function to sexualize real children in real situations and thus continually put their health and wellbeing at risk. In this respect, pornography that symbolically merges youth and sexuality grounds the myth or ideology (Barthes, 1957/1972) that children-and particularly girls—are appropriate objects of desire and legitimate sexual partners. Then, even when symbols of childhood are not implicated in an overtly sexual context (e.g. a little girl wears pigtails and a schoolgirl uniform while playing with her friend after school), the symbols and the child become part of a network of cultural myths of sexuality and sexual yearning.

There are several limitations to this study that should be acknowledged. First, a major challenge in this project was constructing a coding scheme that accurately reflected the nuances of youth sexualized material. During several weeks of creating the coding scheme and training coders, the research team considered and tested a variety of coding schemes. 
Some schemes attempted to code even the most ambiguous words and images as youth sexualized, whereas others only included exemplary cases. Ultimately, the most reliable scheme proved to be one that was also somewhat conservative. For instance, coders did not code for references to "tightness" in this study because those references often refer to a physically-fit body type (e.g. a tight butt). Similarly, coders did not code for women's underwear with pink ribbons or other childlike adornment. Some might argue that women's undergarments, as a genre, often include such adornment without symbolizing youth so much as symbolizing femininity. That said, tightness may also refer to bodies that are youthful, sexually inexperienced, and/or sexually undeveloped, and the hearts and flowers on an actress' lingerie may, regardless of their ubiquity on undergarments designed for adult women, signify sex with young girls. Maintaining the integrity and reliability of content categories while at the same time capturing the essence of the coded material is a significant challenge, especially in an environment where communicators employ subtle and sometimes "in-group" symbols to convey meaning. Future research should continue to explicate the subtleties of youth sexualizing language and imagery to assess the level of its existence and function on adult film covers.

Second, this study is limited by its focus on adult film covers rather than adult film content. Although the covers allow insight into how adult films are framed to the public, and what consumers of pornographic materials see when they are deciding on a purchase, they are not necessarily predictive of adult film content. Thus, this research should be considered a first (rather than definitive) step in the process of assessing the frequency of YSL/YSI in adult and mainstream media. Future content analyses should explore YSL and YSI in adult films, which would allow researchers to assess whether YSL and YSI are more or less prevalent in the packaging of adult films than in the films themselves. Correspondingly, media effects researchers must explore the relationship between consumption of YSL/YSI in pornographic materials (and in other media) and child sexual abuse/pedophilic desires. The perpetuation of deviant sexual beliefs and behaviors may be rooted in or otherwise related to the high frequency of language and imagery that sexualizes youth on adult film covers.

\section{REFERENCES}

Adams, N. G., \& Bettis, P. (2003). Commanding the room in short skirts: Cheering as the embodiment of ideal girlhood. Gender and Society, 17, 73-91.

Adult Video News. (2008). AVN Awards past winners. Retrieved November 29, 2008, from http:// www.avnawards.com/index.php?content=pastwinners

American Psychological Association, Task Force on the Sexualization of Girls (2007). Report of the APA Task Force on the Sexualization of Girls. Washington, DC: American Psychological Association. Retrieved June 20, 2009, from http://www.apa.org/pi/wpo/sexualization.html Bandura, A. (1977). Social learning theory. Englewood Cliffs, NJ: Prentice-Hall.

Bandura, A. (1986). Social foundations of thought and action. Englewood Cliffs, NJ: Prentice-Hall. Barron, M., \& Kimmel, M. (2000). Sexual violence in three pornographic media: Towards a sociological explanation. Journal of Sex Research, 37, 161-168.

Barthes, R. (1972). Mythologies (A. Lavers, Trans.). New York: Hill \& Wang. (Original work published 1957)

Bogaert, A. F., \& Turkovich, D. A. (1993). A content analysis of Playboy centerfolds from 1953 through 1990: Changes in explicitness, objectification, and model's age. Journal of Sex Research, 30, 135-139. 
Child Pornography Prevention, Act S. 1237, 104th Cong. § 1 (1996).

Cook, D. T., \& Kaiser, S. B. (2004). Betwixt and be tween: Age ambiguity and the sexualization of the female consuming subject. Journal of Consumer Culture, 4, 203-227.

Cowan, G., \& Campbell, R. (1994). Racism and sexism in interracial pornography: A content analysis. Psychology of Women Quarterly, 18, 323-338.

Cowan, G., Lee, C., Levy, D., \& Snyder, D. (1988). Dominance and inequality in x-rated videocassettes. Psychology of Women Quarterly, 12, 299-311.

Dietz, P. E., \& Sears, A. (1987/1988). Pornography and obscenity sold in "adult bookstores": A survey of 5132 books, magazines, and films in four American cities. Journal of Law Reform, 21, 7-46.

Driscoll, C. (2002). Girls: Feminine adolescence in popular culture and cultural theory. New York: Columbia University Press.

Durham, M. G. (2008). The Lolita effect: The media sexualization of young girls and what we can do about it. Woodstock, NY: Overlook.

Federal Crimes and Criminal Procedure Rule 18 U.S.C. § 2256 (2006).

Fine, G. A., \& Johnson, B. N. (1980). The promiscuous cheerleader: And adolescent male belief legend. Western Folklore, 39, 120-129.

Foucault, M. (1979). Discipline and punish: The birth of the prison (A. Sheridan, Trans.). New York: Vintage Books.

Gerbner, G., Gross, L., Morgan, M., \& Signorielli, N. (1986). Living with television: The dynamics of the cultivation process. In J. Bryant \& D. Zillman (Eds.), Perspectives on media effects (pp. 97-113). Hillsdale, NJ: Lawrence Erlbaum Associates, Inc.

Giroux, H. A. (1998). Nymphet fantasies: Child beauty pageants and the politics of innocence. Social Text, 57, 31-53.

Giroux, H. A. (2000). Stealing innocence: Corporate culture's war on children. New York: St Martin's Press.

Glascock, J., \& LaRose, R. (1993). Dial-a-porn recordings: The role of the female participant in male sexual fantasies. Journal of Broadcasting and Electronic Media, 37, 311-323.

Glaser, B. G. (1992). Basics of grounded theory analysis: Emergence vs. forcing. Mill Valley, CA: Sociology Press.

Gossett, J. L., \& Byrne, S. (2002). "Click here": A content analysis of Internet rape sites. Gender and Society, 16, 689-709.

Heider, D., \& Harp, D. (2002). New hope or old power: Democracy, pornography and the Internet. Howard Journal of Communications, 13, 285-299.

Higonnet, A. (1998). Pictures of innocence: The history and crisis of ideal childhood. New York: Thames \& Hudson.

Hustler. (Producer) (2008). Barely legal \#82. [Motion picture]. (Available from adultdvdempire.com). Jensen, R. (2007). Getting off: Pornography and the end of masculinity. Cambridge, MA: South End Press.

Jensen, R., \& Dines, G. (1998). The content of mass-marketed pornography. In G. Dines, R. Jensen, \& A. Russo (Eds.), Pornography: The production and consumption of inequality (pp. 66-100). New York: Routledge.

Johnston, F. A., \& Johnston, S. A. (1997). A cognitive approach to validation of the fixatedregressed typology of child molesters. Journal of Clinical Psychology, 53, 361-368.

Kincaid, J. R. (1998). Erotic innocence: The culture of child molesting. Durham, NC: Duke University Press. 
Kleinhans, C. (2004). Virtual child porn: The law and the semiotics of the image. Journal of Visual Culture, 3, 17-34.

Kuhn, A. (1985). The power of the image: Essays on representation and sexuality. London: Routledge.

Lapinski, M. K., \& Rimal, R. N. (2005). An explication of social norms. Communication Theory, 15, $127-147$.

Lederer, L. J. (1995). The price we pay: The case against racist speech, hate propaganda, and pornography. In L. J. Lederer \& R. Delgado (Eds.), The price we pay: The case against racist speech, hate speech, and pornography (pp. 131-140). New York: Hill \& Wang.

Levin, D. E., \& Kilbourne, J. (2008). So sexy, so soon: The new sexualized childhood and what parents can do to protect their kids. New York: Ballantine Books.

Lloyd, B., \& Duveen, G. (1990). A semiotic analysis of the development of social representations of gender. In G. Duveen \& B. Lloyd (Eds.), Social representations and the development of knowledge (pp. 27-46). Cambridge, UK: Cambridge University Press.

MacKinnon, C. A. (1993). Only words. Cambridge, MA: Harvard University Press.

Malamuth, N. M., \& Spinner, B. (1980). A longitudinal content analysis of sexual violence in the best-selling erotic magazines. Journal of Sex Research, 17, 226-237.

Mayall, A., \& Russell, D. E. H. (1990). Racism in pornography. In G. Dines \& J. M. Humez (Eds.), Gender, race and class in media (pp. 167-177). Thousand Oaks, CA: Sage.

McKee, A. (2005). The objectification of women in mainstream pornographic videos in Australia. Journal of Sex Research, 42, 277-290.

Merskin, D. (2004). Reviving Lolita? A media literacy examination of sexual portrayals of girls in fashion advertising. The American Behavioral Scientist, 48, 119-129.

O'Donohue, W., Gold, S. R., \& McKay, J. S. (1997). Children as sexual objects: Historical and gender trends in magazines. Sexual Abuse: A Journal of Research and Treatment, 9, 291-301.

Palmer, C. E. (1979). Pornographic comics: A content analysis. Journal of Sex Research, 15, $285-298$.

Palys, T. S. (1986). Testing the common wisdom: The social content of video pornography. Canadian Psychology, 27, 22-35.

Paul, B., \& Linz, D. G. (2008). The effects of exposure to virtual child pornography on viewers' cognitions and attitudes toward deviant sexual behavior. Communication Research, 35, 3-38.

Prosecutorial Remedies and Other Tools to End the Exploitation of Children Today Act $108^{\text {th }}$ Cong. § 21 (2003).

Rimal, R. N., \& Real, K. (2003). How behaviors are influenced by perceived norms: A test of the theory of normative social behavior. Communication Research, 32, 389-414.

Scott, J. E., \& Cuvelier, S. J. (1987). Sexual violence in Playboy magazine: A longitudinal content analysis. Journal of Sex Research, 23, 534-539.

Scott, J. E., \& Cuvelier, S. J. (1993). Violence and sexual violence in pornography: Is it really increasing? Archives of Sexual Behavior, 22, 357-371.

Shelton, M. L. (1997). Can't touch this! Representations of the African American female body in urban rap videos. Popular Music and Society, 21, 107-116.

Signorielli, N., \& Morgan, M. (2001). Television and the family: The cultivation process. In J. Bryant \& D. Zillman (Eds.), Perspectives on media effects (pp. 333-351). Hillsdale, NJ: Lawrence Erlbaum Associates, Inc.

Smith, D. (1976). The social content of pornography. Journal of Communication, 26, 16-33. 
Strauss, A. L., \& Corbin, J. (1990). Basics of qualitative research: Grounded theory procedures and techniques. Newbury Park, CA: Sage.

Walkerdine, V. (1997). Daddy's girls: Young girls and popular culture. Cambridge, MA: Harvard University Press.

Winick, C. (1985). A content analysis of sexually explicit magazines sold in an adult bookstore. Journal of Sex Research, 21, 206-210.

Yang, N., \& Linz, D. (1990). Movie ratings and the content of adult videos: The sex-violence ratio. Journal of Communication, 40, 28-42.

Robin E. Jensen (PhD, University of Illinois at Urbana-Champaign, 2007) is an Assistant Professor in the Department of Communication at Purdue University. Her research focuses on historical and contemporary discourses surrounding health education policy, sexual health representations, gender equality, and rhetorical history. She teaches courses on health policy rhetoric, research methods, rhetorical history and theory, and feminist and gender studies. Email: rejensen@purdue.edu 